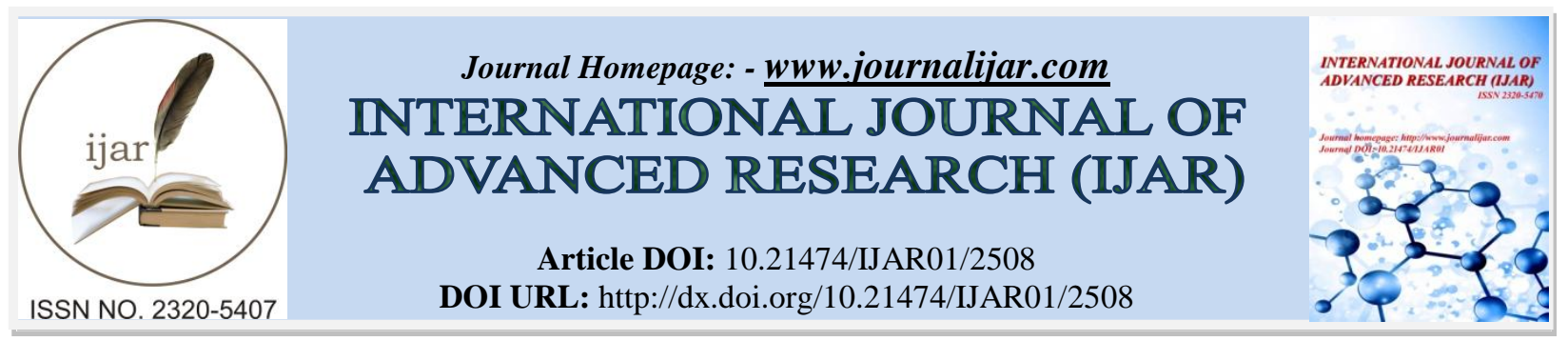

RESEARCH ARTICLE

\title{
RARE DETECTION AND IDENTIFICATION OF METHANOGENIC BACTERIA FROM DIVERSE ECOLOGICAL NICHES IN INDIA FOR CARBON BALANCE AND MANAGEMENT IN OUR ENVIRONMENT
}

\begin{abstract}
Mythili Ravichandran, Prathaban Munisamy, Sharmila Devi Natarajan and Chandrasekar Varadharaju*
Department of Microbiology, K. S. Rangasamy College of Arts and Science, Tiruchengode- 637 215, Tamil Nadu, India
\end{abstract}

\section{Manuscript Info}

\section{Manuscript History}

Received: 25 October 2016

Final Accepted: 23 November 2016

Published: December 2016

Key words:-

Methanogens, Archaebacteria, Carbon

dioxide, Carbon balance, Carbon

Management, Biofuel

\section{Abstract}

The continuous emission of Green House Gas (GHG) predominantly carbon dioxide $\left(\mathrm{CO}_{2}\right)$ in the atmosphere becomes a major concern and also gaining much attention in the environmental agenda. Sequestration of $\mathrm{CO}_{2}$ is one of the major new and safe methods for such efforts which help the balance of carbon cycle in our environment. Methanogenic archaea is one of the natural encounters for sequestration of $\mathrm{CO}_{2}$. They are strict anaerobic, and the most diverse archaebacteria. Among all microbes, methanogenic bacteria are poorly characterized by means of isolation and identification. The present research is mainly prominent to isolate and identify the prospective methanogenic bacteria from different ecological niches of India. Three methanogenic bacterial isolates such as MET 1, MET 2 and MET 3 were observed, isolated and identified based on their different microbiological methanogenic investigations such as microscopic analysis, gas detection, substrate utilization and morphological identification. These methanogens are further used for effective carbon dioxide sequestration and enhanced biofuel production.

Copy Right, IJAR, 2016,. All rights reserved.

\section{Introduction:-}

The methanogenic bacteria are the strict anaerobes, and they are also recognized as a scientific member of the domain Archaea. Methanogenic archaea has taken a core place in the modern ecology and biochemistry research. It plays a key role in anoxic environments by carrying out the last step of anaerobic decomposition (methanogenesis) of organic matter, mineralization into methane and carbon dioxide (Joulian et al., 1998), by using a limited number of substrates such as carbon dioxide and hydrogen, formate, acetate, methanol and methylamines (Cavicchioli et al., 2003). Methanogenesis plays a vital role in the cycling of carbon in several ecosystems (Antony et al., 2012). Methanogens are difficult to isolate because some members require long incubation periods for their growth and some are rarely difficult to separate from their syntrophic partners (Issazadeh et al., 2013).

Methanogenic bacteria are tentatively identified by microscopic analysis and use of substrates. They are differentiated from non-methanogens based on their auto-fluorescence under ultraviolet illumination (Mink and Dugan, 1977).Methanogenic archaea possess some of the unique coenzymes such as $F_{420}$ (Cheeseman et al., 1972) and coenzyme M (McBride and Wolfe, 1971) for their identification. These substances showed as blue-green 
fluorescence in the oxidized state and were non-fluorescent in the reduced form. In addition, two more cofactors, yellow fluorescent compound and $\mathrm{F}_{350}$, were also used for their easy and improved identification(Doddema and Vogels, 1978).

Carbon dioxide Capture, Sequestration, Utilization and Conversion (CCSUC), better concept of turning a greenhouse gas into an expedient feedstock, is currently receiving more exquisite courtesy for mitigation of greenhouse gas carbon dioxide. It is a new and environmental sound approach (Riahi et al., 2004; Jajesniak et al., 2014). Driven by green itinerary and government commitment to reducing carbon food print, we use anoxic microbial carbon capturing technique to convert $\mathrm{CO}_{2}$ into fuels and value- added chemicals (Styring and Armstrong, 2011). This research endeavor on anoxic microbial CCSUC has started to gain its momentum. One opportunity is to utilize carbon dioxide - reducing methanogens, for Biological methane production (BMP), which are an intriguing group of archaeal candidate for conversion of hydrogen and carbon dioxide to methane (Rittmann et al., 2013).

The aim of this study was to isolate and tentatively identify the methanogenic bacteria from different ecological niches using epifluorescence microscopy.

\section{Materials and Methods:-}

Source sites and sample collection:-

Five different samples were collected from various ecological niches (marine sediments, marshy soil) of Thandavaroya Cholapuram, Chidambaram, Tamil Nadu, India. These samples were used as the source of methanogenic bacteria isolation. The samples were collected aseptically in sterile, pre-gassed (or filled with nitrogen to displace the existing air), sealed containers. These samples were immediately transferred and sealed to the prescribed containers to minimize the exposure of oxygen contamination (Ranade and Gadre, 1988).

\section{Growth media:-}

As methanogenic bacteria are extremely sensitive towards oxygen, they require reducing environments, strict anoxic conditions, and pre-reduced media. These are essential for their growth and isolation. Anaerobic techniques originally developed by Hungate (Hungate, 1950; Hungate, 1969) modified by Miller and Wolin (1974) and further described by Ranade and Gadre (1988) were followed for media preparation, isolation, and purification. Anaerobic microbial cells were grown in serum vials $(35.5 \mathrm{ml}$ or $118 \mathrm{ml})$ closed with butyl rubber stoppers and sealed with an aluminum seal (Balch and Wolfe, 1976) or in $500 \mathrm{ml}$ serum bottles with serum caps (diameter $35 \mathrm{~mm}$ ). $\mathrm{The}_{2}+$ $\mathrm{CO}_{2}$ were used as a substrate in 80:20 ratios for isolation of carbon dioxide-reducing methanogens. This substrate also acts as a gas phase for further processing (Sowers, 1995; Sowers and Schreier, 1995).

\section{Sample enrichment:-}

The five samples were inoculated $\left(\sim 1-5 \%\right.$, v/v) into the sodium bicarbonate media $\left(\mathrm{CO}_{2}-\mathrm{H}_{2}, 20: 80\right)$ and it was incubated at $37^{\circ} \mathrm{C}$ for 15 days for enrichment (Ranade and Gadre, 1988). Following the enrichment process, methanogens were enumerated and isolated by a dilution-to-extinction enrichment culture method (Leadbetter and Breznak, 1996). Normally 7-20 days are needed for the suitable growth of methanogenic bacteria. The growth of methanogens was monitored and confirmed by observing turbidity, use of substrates, and formation of methane gas. Normally, numerous transfers (approximately 5-10 transfers) are obligatory for better purification. The pure cultures were subcultured (10\% inoculum) for further processing.

\section{Purification of methanogenic archaea: roll tube:-}

A simple and efficacious technique for purification of methanogens was originally developed by Hungate (1950, 1969). This is called roll tube technique. It is one of the scientific foundations for the cultivation of methanogens. The enumeration of methanogenic populations was conducted by the roll tube technique in which the blue autofluorescent colonies were counted as methanogenic bacteria (Adachi et al., 1996; Adachi, 1999). Single-colony picking from roll tube culture was followed as the easiest method. Well-developed colonies were appeared on the surface of the roll tube. The stopper of the roll-tube culture was removed and oxygen free Nitrogen and Carbon dioxide $(80: 20 \mathrm{v} / \mathrm{v})$ gas mixture was passed through the roll-tube and the bottle with liquid medium kept for inoculation. The selected colony was removed with a sterile syringes fitted with $261 / 2$ gauge needle or LP needle, and the tip of which was bent at $90^{\circ}$ angle. The tip was placed over the colony and pressed in as gentle suction was applied to draw it into the needle tip. The colony was picked with the needle, then transferred to the fresh medium, sealed, gassed and incubated at an appropriate temperature. After a period of growth, the purity of the culture was monitored and checked properly. The purity of the isolate was checked by means of re-isolation in a roll tube. The 
isolates were subcultured every 2 -week interval onto sodium bicarbonate medium. The stock slants were prepared with $4 \mathrm{ml}$ of agar medium in serum bottles. The cultures were reviewed by injecting $0.5 \mathrm{ml}$ of sterile medium to wash off the cells and then 0.1 to $0.2 \mathrm{ml}$ was withdrawn and injected into sterile liquid medium (Hungate et al., 1966;Balch and Wolfe, 1976; Balch et al., 1979; Ranade and Gadre, 1988; Adachi, 1999; Wolfe, 2011; Issazadeh).

\section{Tentative identification tools for isolated methanogens:-}

In general, the methanogenic bacteria are poorly characterized ones. However, some of the distinct morphological and physiological approaches are essential for their characterization. Some of the collective tentative and confirmatory identification tools are indigenously introduced, which helps easy identification of methanogenic bacteria.

\section{Morphological and physiological traits:-}

Aerobic media test (lack of growth in aerobic medium):-

Purity of the methanogenic bacteria was tentatively confirmed by inoculating the strains into aerobic broth. The isolated culture is obligate anaerobes, and then it does not grow in the aerobic media. So, this was considered as a supportive identification tool.

\section{Anaerobic media test: lack of growth in glucose medium:-}

Purity of the methanogenic isolates was confirmed by inoculation of strains into an anaerobic medium for heterotrophic bacteria, which contained glucose $5.0 \mathrm{~g}$, polypeptone $1.0 \mathrm{~g}$, and $\mathrm{NaHCO}_{3} 0.8 \mathrm{~g}$ in $1000 \mathrm{ml}$ the basal solution (head gas phase in test tubes: $\mathrm{N}_{2}$ ). Those cultures did not show growth after the 45 days of inoculation were considered as pure cultures (Adachi, 1999).

\section{Growth in liquid culture:-}

Generally, the growth of methanogens is very slow. The methanogenic isolates were inoculated in bicarbonate broth. The growth of colonies in liquid bicarbonate culture was monitored and noted. The methanogens were grow, after 14 days of incubation at $30^{\circ} \mathrm{C}$, those isolates were classified as grow fast. The isolates that formed visible colonies after 30 or more days of incubation were classified as grow slow. Those that grew intermediately were classified as grow medium (Adachi, 1999).

\section{General Morphology and motility:-}

In many cases, motility, cell shape and size were observed in wet mounts. Cultures from different growth phases should be examined. Hanging drop preparations may be used, preferably prepared in an anaerobic laboratory and observed there by using a light microscope (Boone and Whitman, 1988).

\section{Gram character:-}

In this morphological trait, Gram-positive, Gram-negative, Gram-variable, or Gram-nonreactive characters of methanogens were studied. Most of the methanogenic strains are Gram negative ever since they are bacteria without cell wall. Gram staining was performed by the Hucker or the Burke method and the results should be compared with results for known gram- positive and gram-negative control organisms.

Physiological traits were also used for identification of the growth conditions of methanogens. This identification is based on the optimum temperature, $\mathrm{pH}$, and type of substrates. Enrichment of methanogens with different defined substrates is the supportive tools to identify the types of methanogens.

\section{Gas production:-}

Generally, in methanogenic bacterial metabolism, the obligatory production of unique gaseous hydrocarbonmethane is an end-product from a relatively narrow range of substrates for their energy metabolism. After 15 days of incubation, the head space of the culture vessels containing total methane gas production was checked. Some of the following methods were used for checking gas production for tentative identification (Whitman et al., 2006). 


\section{Moisture syringe method:-}

Moisture syringe method is one of the tentative identification tools. After the end of proper incubation period, the total gas content was analyzed by moisture syringe method. In this method, a $5 \mathrm{ml}$ syringe moistened with a drop of sterile water with a plunger is taken and inserted on to the bottle. The excess gas in the culture bottle is allowed to flow in the syringe and methane gas is analyzed and measured.

\section{Flame test:-}

Flame test is another tentative confirmative technique for confirming methane production. In this process, methane gas is sucked through a sterile $2 \mathrm{ml}$ syringe with needle. In the culture bottle, the head space containing the methane gas is plungered and injected on flame. The culture containing pure methanogens, based on their metabolism of pure methane gas, is produced and flamed with bluish color.

\section{Water displacement method:-}

Methane gas production is also observed through a water displacement unit connected to the culture vials. The production of the methane gas during methanogenesis pathway is observed through bubble formation in the water displacement unit. Gas chromatography technique is also one of the confirmatory tools for identification of methanogens (Mishra, 1954).

\section{Use of antibiotics:-}

Vancomycin is used for purification and identification of methanogens. We prepared $10 \mu \mathrm{g} / \mathrm{ml}$ concentration of vancomycin and it was sterilized by filter sterilization method. It has to be inoculated into bicarbonate media. The growth of the methanogenic isolates was checked periodically.

\section{Microscopic analysis:-}

Generally, microscopic methods are used for tentative identification of methanogenic bacteria. The process studied so far is primary screening methods. The microscopic identification methods are always validated as confirmatory methods in the case of methanogenic identification.

\section{Epifluorescence microscopy:-}

Epifluorescence microscopy is one of the prominent techniques. It has been facilitated as qualitative identification tool and also used for reviewing methanogenic ecology. $\mathrm{F}_{420}$ is one of the electron carriers that are mainly found in methanogenic bacteria. The presence of these unique biochemical markers, cofactor $\mathrm{F}_{420}$, is found to be in higher concentration in methanogens rather than other eubacteria. It gives a tentative viable count such as morphology of predominant methanogenic species (Cheeseman et al., 1972; Edmondson et al., 1972).

Colonies showing fluorescence under fluorescent microscope (NIKON) equipped with $\mathrm{Hg}$ lamp at excitation at $420 \mathrm{~nm}$ and $430 \mathrm{~nm}$. The isolates were then transferred to methanogenic liquid media. The cultures were tested for purity using fluorescent microscopy after growth.

\section{Results:-}

Isolation of methanogenic bacteria:-

Following enrichment of the collected samples, minimum 5-10 repeated transfers were carried out to reduce the load of microbial contamination. Those enriched samples were serially diluted and roll-tubed for purification. Seven morphologically distinct colonies were picked up from the roll tube for single-colony transfer technique. Among them, only five isolates showed growth in appropriate medium and were termed as MET 1, MET 2, MET 3, MET 4, and MET 5. These isolates were studied for further confirmation.

\section{Supportive tools for easy identification of methanogens:-}

All the five potential isolates (table1) were checked for methanogens by using some of the tentative supportive tools and it was done for its easiest analysis.

\section{Aerobic and Anaerobic (Glucose) media test:-}

Table 2 shows the aerobic and anaerobic media tests for five isolates tested. All five isolates did not show any growth in aerobic medium. So, those were confirmed as strict anaerobes. Because methanogens are obligate anaerobes, in anaerobic media test, all isolates (i.e., MET 1, MET 2, MET 3, MET 4, and MET 5) did not show any characteristic growth in the heterotrophic glucose medium. In this study, the growth of methanogen was also 
studied. Generally, the growth of methanogens is slow. The methanogenic isolates MET 1, MET 3, and MET 5, which formed visible colonies in liquid culture after 14 days of incubation at $30^{\circ} \mathrm{C}$, were classified as "grow fast." Isolate MET 4, which formed visible colonies after 30 days or more of incubation, was classified as "grow slow." Isolate MET 2, which grew intermediately, was classified as "grow medium."

\section{Morphological traits (wet mount and Gram character):-}

Table 3 and Figure 4 depict, the five isolates observed for morphological traits using Gram reaction. Of these, MET 1, MET 2, MET 4, and MET 5 were confirmed to be Gram negative isolates, and MET 3 alone was confirmed as Gram positive. Owing to this, most of the methanogens were classified as Gram negative due to lack of peptidoglycan layer. MET 1 and MET 5 were identified as motile, long rods. MET 2 and MET 5 were confirmed as non-motile, short rods. MET 4 was observed as Gram-positive rod shaped.

\section{Physiological traits (substrate, gas phase, $\mathrm{pH}$, temperature):-}

Table 3 gives a detailed description of physiological traits such as types of substrate, gas phase, $\mathrm{pH}$ range, and optimum temperature. All the five isolates used $\mathrm{H}_{2} / \mathrm{CO}_{2}(80: 20)$ as a substrate and also a gas phase. Because the hydrogenotrophic methanogens use hydrogen and carbon dioxide as a substrate and gas phase, all the methanogenic isolates grew well at optimum temperature of $37^{\circ} \mathrm{C}$ and $\mathrm{pH}$ of 7.0 . These characteristics were used to identify the types of methanogens.

\section{Gas production:-}

After 15 days of incubation, production of methane was tentatively checked by using the moisture syringe method. Among the five, four methanogenic isolates (MET 1, MET 2, MET 4, and MET 5) showed positive results for gas detection. Difference was found with isolate 4 (MET 4). This was further confirmed with the upcoming tests. In flame and water displacement methods, three isolates (MET 1, MET 3, and MET 5) showed blue flaming due to the presence of methane. In contrast, isolates MET 2 and MET 4 showed negative results for gas production. The presence of methane gas was confirmed based on their ability to produce methane by gas chromatography. It is one of the tentative, improved methods for methanogen identification.

\section{Use of vancomycin:-}

To study vancomycin-resistant characters of five isolates, an antibiotic susceptibility study was carried out. Table 5 depicts the resistance attributes of the five isolates against vancomycin. Out of these, MET 1, MET 3, and MET 5 showed characteristic growth in vancomycin. In contrast, MET 2 and MET 5 showed no growth. This test was also served as a purity checker. Among the isolates, MET 1, MET 3, and MET 5 were tentatively confirmed as methanogenic isolates, which was further confirmed by microscopic analysis.

\section{Microscopic analysis of methanogenic bacteria:-}

Figure 5 shows the results of bluish-green auto-illumination of tentatively confirmed methanogenic isolates in the roll tube under an epifluorescence microscope. Three potential methanogenic isolates (MET 1, MET 3, and MET 5) showed auto fluorescence under UV illumination. In the broth culture also the same three isolates were shown positive for auto-illumination under the epifluorescence microscope. In contrast, the other two isolates were identified as nonmethanogenic flora. 


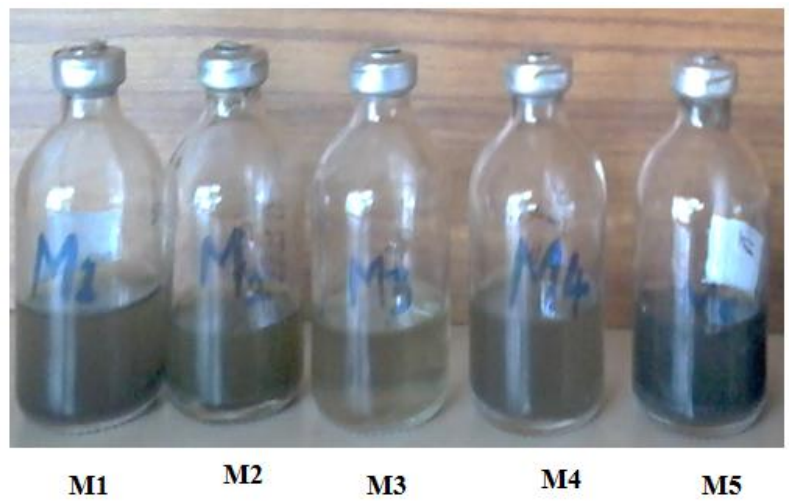

Fig 1: Enrichment of methanogens in sodium bicarbonate medium supplemented with $\mathrm{CO}_{2}+\mathrm{H}_{2}$ (20:80)

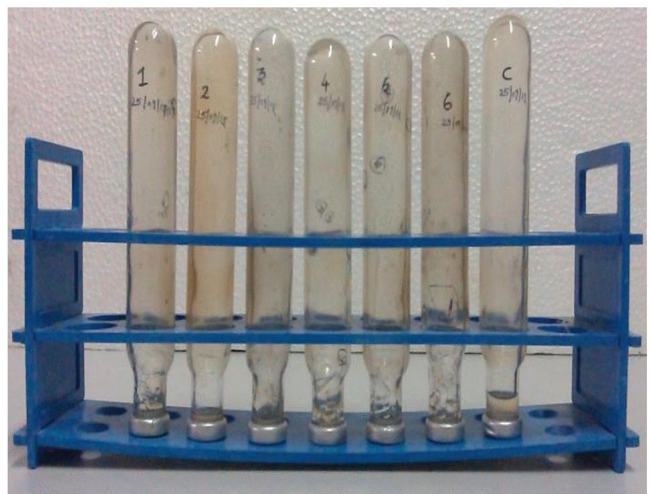

(A) Roll tube

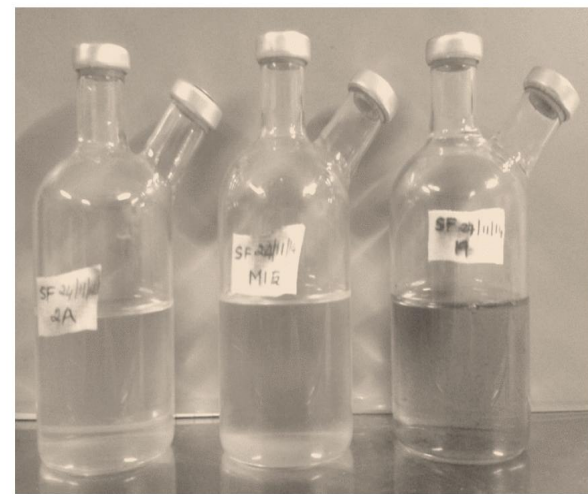

(B) Double-armed neck bottles

Fig 2: Purification of methanogens by using a roll tube and double-armed neck bottles.

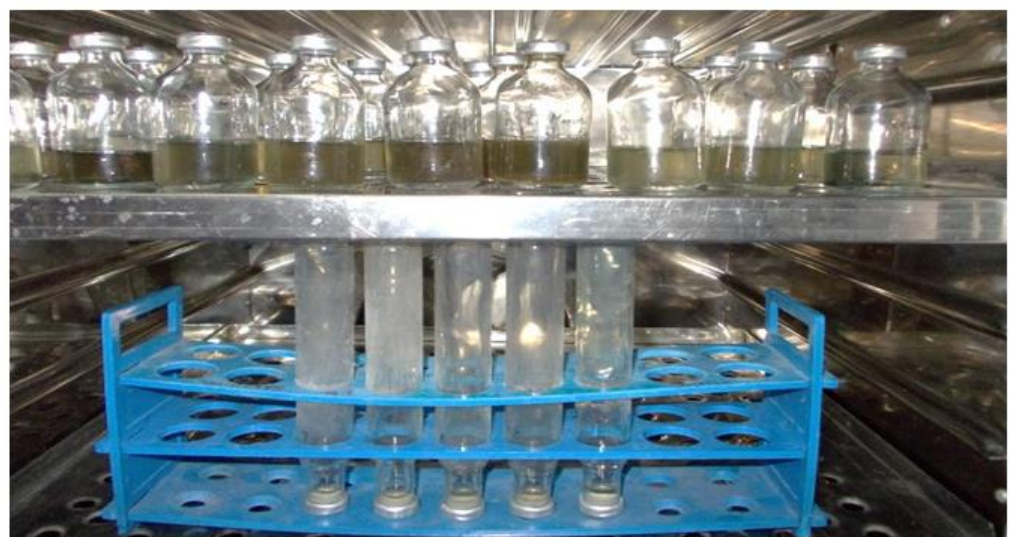

Fig 3: Enriched methanogenic samples are incubated under appropriate (mesophilic) conditions. 

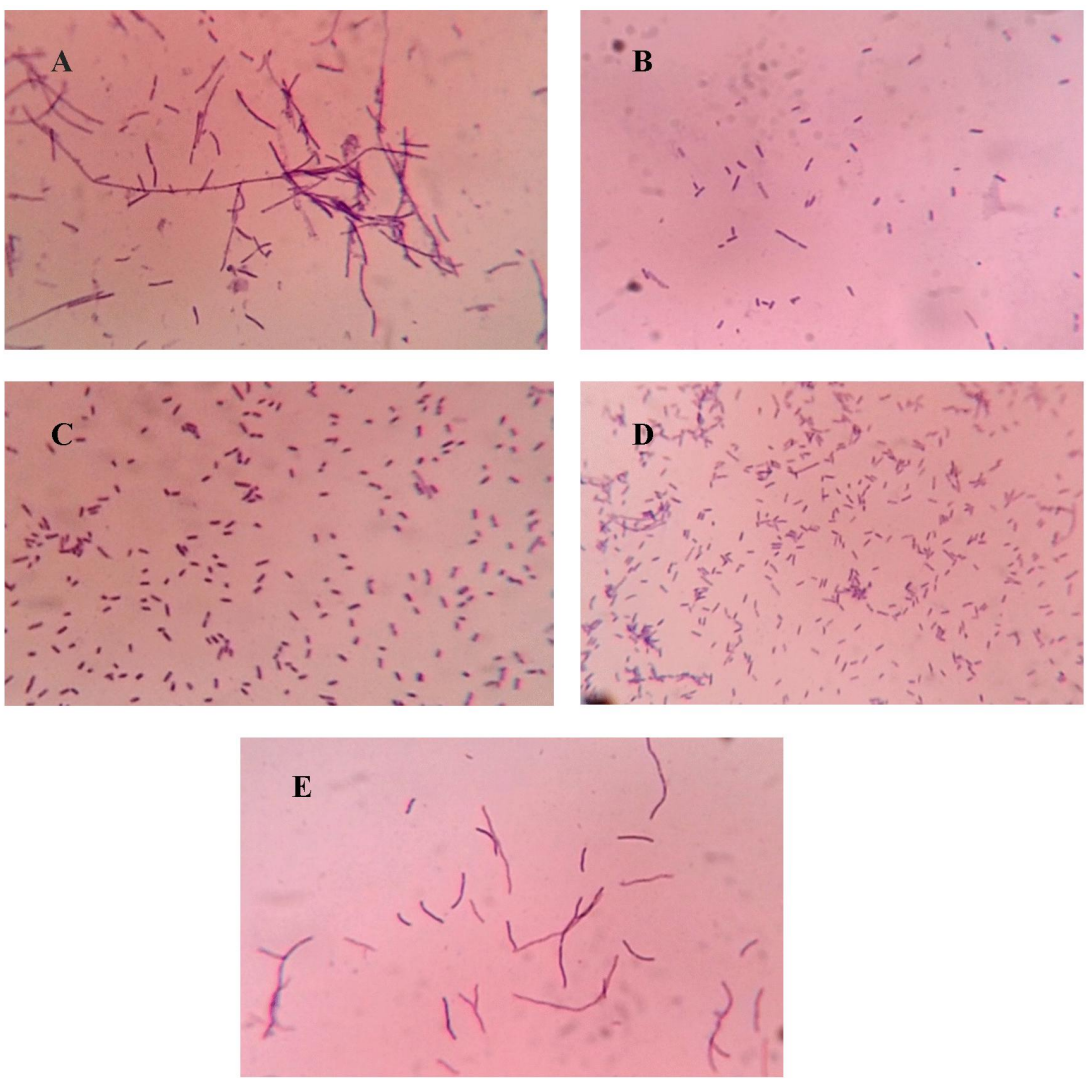
A. Gram-negative long rods
B. Gram-negative short rods C. Gram-negative short rods
D. Gram-positive rods
E. Gram-negative long rods

Fig 4: Gram reaction results of methanogenic isolates under 100× objective. 


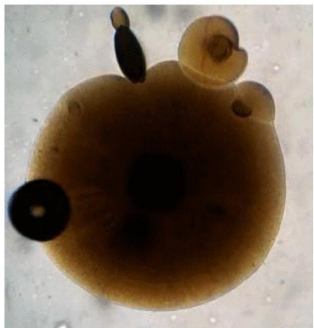

A (1)

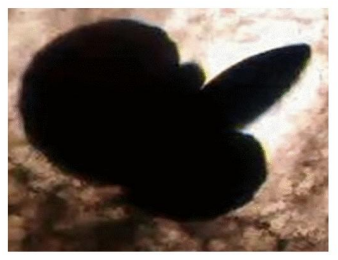

B (1)

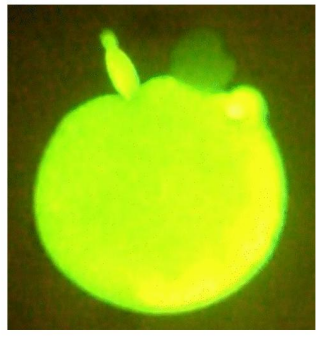

A (2)

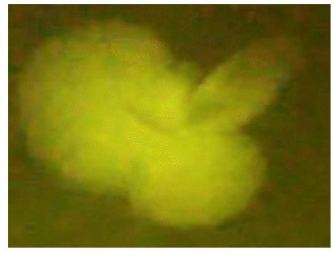

B (2)

A (1), B (1): Methanogenic isolates in light phase under epifluorescence microscope (10×)

A (2), B (2): Methanogenic isolates in fluorescence phase under epifluorescence microscope $(10 \times)$

Fig 5: A bluish-green auto-fluorescence colonies (left) showing methanogens and corresponding bright field microscope (right) 


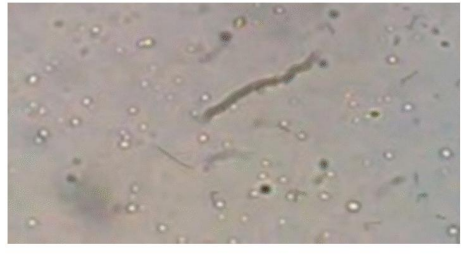

A (1)

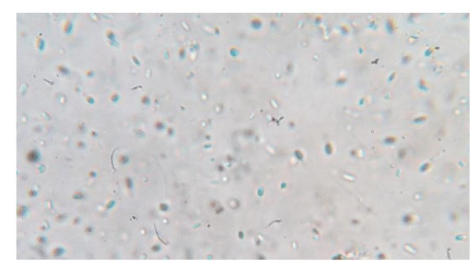

B (1)

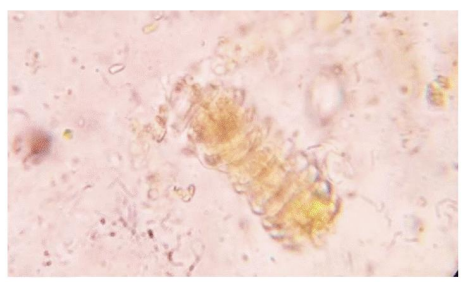

C (1)

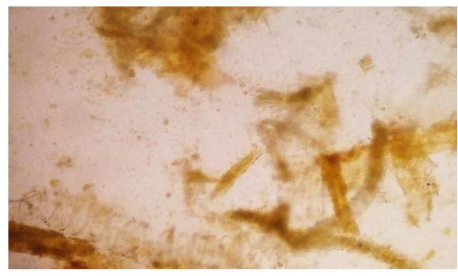

D (1)

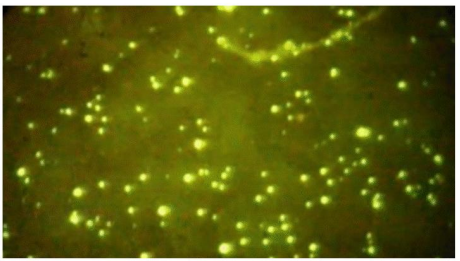

A (2)

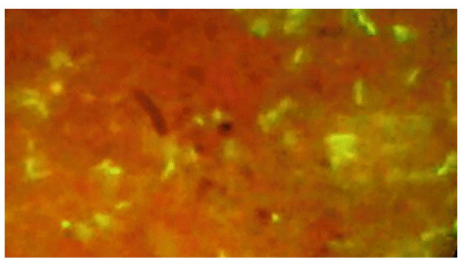

B (2)

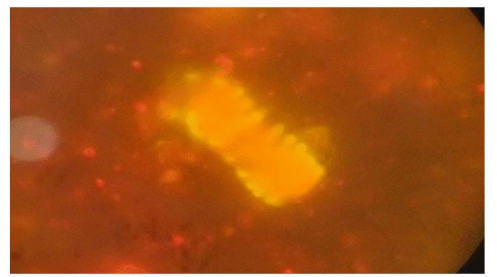

C (2)

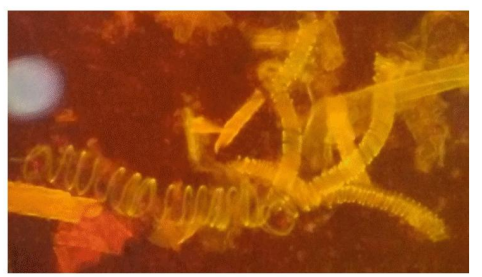

$\mathrm{D}(2)$

A (1), B (1), C (1), and D (1): Methanogenic isolates in fluorescence phase under epifluorescence microscope $(100 \times) \mathrm{s}$

A (2), B (2), C (2), and D (2): Methanogenic isolates in light phase under epifluorescence microscope $(100 \times) \mathrm{s}$

Fig 6: Optical and fluorescent microphotographs of methanogenic bacterial colony under epifluorescence and corresponding bright-field microscope under oil immersion (100x)

Table 1: Overview of methanogenic bacteria sample processing report

\begin{tabular}{|c|c|l|c|}
\hline S. No. & Sample ID No. & \multicolumn{1}{|c|}{ Sample type } & No. of isolates \\
\hline 1 & MET 1 & Marine sediment & 3 \\
\hline 2 & MET 2 & Marine sediment & - \\
\hline 3 & MET 3 & Marine sediment & 1 \\
\hline 4 & MET 4 & Marshy soil & - \\
\hline 5 & MET 5 & Marshy soil & \\
\hline
\end{tabular}


Table 2: Growth in aerobic and anaerobic media and liquid cultures

\begin{tabular}{|c|c|c|c|l|}
\hline S. No. & Sample ID No & $\begin{array}{c}\text { Growth in aerobic } \\
\text { medium }\end{array}$ & $\begin{array}{c}\text { Growth in anaerobic } \\
\text { (glucose) medium }\end{array}$ & $\begin{array}{c}\text { Growth in liquid } \\
\text { cultures }\end{array}$ \\
\hline 1 & MET 1 & - & - & Grow fast \\
\hline 2 & MET 2 & - & - & Grow medium \\
\hline 3 & MET 3 & - & - & Grow fast \\
\hline 4 & MET 4 & - & - & Grow slow \\
\hline 5 & MET 5 & - & - & Grow fast \\
\hline
\end{tabular}

Table 3: Some of the supportive tools (morphological and physiological traits) for easy identification of methanogenic bacteria

\begin{tabular}{|l|l|l|l|l|l|l|}
\hline \multirow{2}{*}{\begin{tabular}{l} 
Sample ID \\
\cline { 2 - 7 }
\end{tabular}} & \multicolumn{2}{|c|}{ Morphological traits } & \multicolumn{5}{c|}{ Physiological traits } \\
\hline M1 & Let mount character & Gram character & $\begin{array}{l}\text { Substrate } \\
\mathrm{H}_{2} / \mathrm{CO}_{2} \\
(80: 20)\end{array}$ & Gas phase & pH & $\begin{array}{l}\text { Temperature } \\
\left({ }^{\circ} \mathrm{C}\right)\end{array}$ \\
\hline M2 & Short rods, nonmotile & Gram negative & $\begin{array}{l}\mathrm{H}_{2} / \mathrm{CO}_{2} \\
(80: 20)\end{array}$ & $\begin{array}{l}\mathrm{H}_{2} / \mathrm{CO}_{2} \\
(80: 20)\end{array}$ & 7.0 & 37 \\
\hline M3 & Short rods, nonmotile & Gram negative & $\begin{array}{l}\mathrm{H}_{2} / \mathrm{CO}_{2} \\
(80: 20)\end{array}$ & $\begin{array}{l}\mathrm{H}_{2} / \mathrm{CO}_{2} \\
(80: 20)\end{array}$ & 7.0 & 37 \\
\hline M4 & Rods, nonmotile & Gram negative & $\begin{array}{l}\mathrm{H}_{2} / \mathrm{CO}_{2} \\
(80: 20)\end{array}$ & $\begin{array}{l}\mathrm{H}_{2} / \mathrm{CO}_{2} \\
(80: 20)\end{array}$ & 7.0 & 37 \\
\hline M5 & Long rods, motile & Gram negative & $\begin{array}{l}\mathrm{H}_{2} / \mathrm{CO}_{2} \\
(80: 20)\end{array}$ & $\begin{array}{l}\mathrm{H}_{2} / \mathrm{CO}_{2} \\
(80: 20)\end{array}$ & 7.0 & 37 \\
\hline
\end{tabular}

Table 4: Some of the tentative tools for improved identification of methanogenic bacteria

\begin{tabular}{|l|l|l|l|}
\hline \multirow{2}{*}{ Sample ID No } & \multicolumn{3}{|c|}{ Gas production } \\
\cline { 2 - 4 } & Moisture syringe method & Flame test & Water displacement technique \\
\hline M1 & + & + & + \\
\hline M2 & + & - & - \\
\hline M3 & + & + & + \\
\hline M4 & - & - & - \\
\hline M5 & + & + & + \\
\hline
\end{tabular}

Table 5: Use of vancomycin for checking purity of methanogenic bacteria

\begin{tabular}{|c|c|c|}
\hline S. No & Sample ID No & Growth in vancomycin \\
\hline 1 & M1 & + \\
\hline 2 & M2 & - \\
\hline 3 & M3 & + \\
\hline 4 & M4 & + \\
\hline 5 & M5 \\
\hline
\end{tabular}

Table 6: Tabular view of microscopical analysis of tentative identification of methanogenic archaea

\begin{tabular}{|l|l|l|}
\hline S. No & Sample ID No & $\begin{array}{l}\text { Epifluorescent microscopical } \\
\text { analysis }\end{array}$ \\
\hline 1 & M1 & Fluorescent \\
\hline 2 & M2 & Non-fluorescent \\
\hline 3 & M3 & Fluorescent \\
\hline 4 & M4 & Non-fluorescent \\
\hline 5 & M5 & Fluorescent \\
\hline
\end{tabular}




\section{Discussion:-}

The tentative techniques described in this study offer a number of practical advantages in culturing methanogenic bacteria. Media were prepared using standard anaerobic methodology (Hungate 1950, 1969) with slight modifications.

In this study, seven potential colonies on roll tube cultures were subjected to isolation by single-colony picking method and subsequent sub-culturing. The five isolates only were hardly grown on the medium after the transfers. Among the seven isolates, two colonies did not show any growth after the transferring (Singh and Mazumder, 2010). The remaining five potential strains that showed growth were subjected to the tentative identification tests. Then, the methane production tentatively confirmed positive methanogenic isolates were further taken for confirmatory test and also for the active biofuel production (Adachi, 1999). All the five isolates showed negative results in aerobic and heterotrophic anaerobic (glucose) media. Again, among these five isolates, three showed fast growth, one showed slow growth, and one showed negative result.

According to Gram reaction, most of the isolates showed Gram-negative, motile/nonmotile, longer to smaller rods because their cell walls lacked peptidoglycan layer. It can be concluded from these observations that in Gram stain reaction of a mixed microbial population containing methanogen and nonmethanogenic bacteria, the results showed that mostly methanogens are Gram negative and non-methanogenic bacteria are Gram positive(Todar, 2009). Some exception is also there (e.g., pseudomurein-containing Methanobacterium formicicum).

To identify types of methanogens (hydrogenotrophic, acetoclastic, methylotrophic), characteristics such as the type of substrate and gas phase are very important. On the basis of the substrate use, gas phase can be chosen. Temperature and $\mathrm{pH}$ are also important for further classification and incubation. In our test, three tentatively identified methanogens were used $\mathrm{H}_{2} / \mathrm{CO}_{2}(80: 20)$ as a substrate and gas phase for carbon and energy source. So those were proved to be hydrogenotrophic, carbon dioxide-reducing methanogens. These isolates grew well at $37{ }^{\circ} \mathrm{C}$ (mesophilic methanogens) and $\mathrm{pH}$ of 7.0.

Generally in methanogenic bacterial metabolism, the obligatory production of unique gaseous hydrocarbon methane is an end-product from a relative range of substrates for their carbon and energy metabolism. To identify active methanogens, methane gas was detected after 15 days of incubation by using tentative tools such as moisture syringe method, flame method and water replacement method, and confirmatory tool such as gas chromatography. In this, tentative gas-detecting tools were used for easy identification. Most of the isolates showed positive results for gas production.

According to antibiotic resistance studies, three isolates exhibited positive result due to lack of cell walls. Methanogens are resistant to antibiotics such as penicillin G, D-cycloserine, cephalosporin C, vancomycin, and mixtures of these antibiotics, which inhibit the synthesis of cell walls in bacteria. Owing to this feature, methanogens show growth only in vancomycin-added medium (Garcia et al., 2000; Whitman et al., 2006).

Of the five isolates, only three (MET 1, MET 3, and MET 5) showed the auto-fluorescence under the epifluorescence microscope. Fluorescence is one of the presumptive characteristics of methanogens. For easy enumeration, colonies were observed on roll tube the under epifluorescence microscope in UV light. We observed that majority of illuminated colonies were methanogenic bacteria and all non-illuminating colonies were nonmethanogenic bacteria. Although, the rate at which the fluorescence faded varies from species to species, there is a chance that there are non-methanogenic bacteria that have no $\mathrm{F}_{420}$ or only low levels, or, on the contrary, that there are nonmethanogenic bacteria that exhibit similar low-level $\mathrm{F}_{420}$ cofactor. In this way, such anaerobes have not yet been observed.

Auto-fluorescence at 420nm excitation was greenish yellow, at $350 \mathrm{~nm}$ it was bluish white. Generally, fluorescence due to excitation at $420 \mathrm{~nm}$ is stronger than that at $350 \mathrm{~nm}$. Fluorescence was dull on illumination at both wavelengths but faded more quickly at excitation at $350 \mathrm{~nm}$. Fading of the fluorescence of $\mathrm{F}_{420}$ might be caused by photo-reduction, which is also observed for other deazaflavins. After a brief period in the dark, the fluorescence at $420 \mathrm{~nm}$ was restored to its original level. The fluorescence at $350 \mathrm{~nm}$ did not reappear(Doddema and Vogels, 1978). 
The use of UV light fluorescence selection also increases speed and sensitivity. It is one of the conventional methods. Preliminary research studies indicate that the fluorescence is still present $24 \mathrm{~h}$ after exposure of the cells to oxygen. Although the fluorescence does fade after exposure to UV light, removing the light for a few minutes and then returning the light generally results in fluorescence. The microscopic analysis served as one of the evidence for methanogenic bacteria, but definitive proof is required for further characterization (Edwards and McBride, 1975; Kataoka et al., 1991).These identification techniques offer a simple, rapid, and sensitive method for easy and improved isolation and enumeration of methanogenic bacteria.

\section{Conclusion:-}

A potential analysis of this study concluded that among five isolates three isolates (i.e., MET1, MET3 and MET5) were methanogenic flora based on certain microbiological analysis. These three isolates showed positive results for tentative identification. All the three isolates were identified as rods based on Gram stain reaction. These three were auto-illuminated bluish-green under UV light. It is confirmed that the majority of blue-auto-fluorescent colonies on roll tube were methanogens. However, further studies on biogas production need to be conducted to develop more effective biofuel production. Therefore, the results of this study may create more interest in the cultivation and biofuel production in anoxic sediments.

\section{Acknowledgment:-}

We acknowledge the financial support provided by the Department of Science and Technology (DST), New Delhi. We also acknowledge the academic and team support by the K.S. Rangasamy College of Arts and Science.

\section{Conflict of Interest:-}

The authors declare that they have no conflict of interest regarding this work.

\section{References:-}

1. Adachi, K. Isolation of hydrogenotrophic methanogenic archaea from a subtropical paddy field. FEMS Microbiol Ecol., 1999; 30: 77-85.

2. Adachi, K., Oyediran, G., Senboku, T. Effect of application of rice straw and cellulose on methane emission and biological nitrogen fixation in a subtropical paddy field. II. Enumeration of populations of methanogenic bacteria by most probable number method and roll tube method. Soil Sci Plant Nutr., 1996; 42: 713-23.

3. Antony, C.P., Doronina, N.V., Boden, R., Trotsenko, Y.A., Shouche, Y.S., Murrell, J.C.Methylophaga lonarensis sp. nov., a moderately haloalkaliphilic methylotroph isolated from the soda lake sediments of a meteorite impact crater. Int J Syst Evol Microbiol., 2012; 62: 1613-18.

4. Balch, W.E., Fox, G.E., Magnum, L.J., Woese, C.R., Wolfe, R.S. Methanogens: re-evaluation of a unique biological group. Microbiol Rev., 1979; 43:260-96.

5. Balch, W.E., Wolfe, R.S. New approach to the cultivation of methanogenic bacteria: 2- mercaptoethanesulfonic acid (HS-CoM)-dependent growth of Methanobacterium ruminantium in a pressurized atmosphere. Appl Environ Microbiol., 1976; 32: 781-91.

6. Boone, D.R., Whitman, W.B. Proposal of minimal standards for describing new taxa of methanogenic bacteria. Int J Sys Bacteriol., 1988; 38: 212-19.

7. Cavicchioli, R., Curmi, P.M., Saunders, N., Thomas, T. Pathogenic archaea: do they exist? Bioessays., 2003; 25: 1119-28.

8. Cheeseman, P., Toms-Wood, A., Wolfe, R.S. Isolation and properties of a fluorescent compound, factor 420, from Methanobacterium strain M.o.H. J Bacteriol., 1972; 112: 527-31.

9. Doddema, H,J., Vogels, G.D. Improved identification of methanogenic bacteria by fluorescence microscopy. Appl Environ Microbiol., 1978; 36: 752-54.

10. Edmondson, D.E., Barman, B., Tollin, G. On the importance of the N-5 position in flavin coenzymes. Properties of free and protein bound 5-deaza analogs. Biochemistry., 1972; 11: 1133-1138.

11. Edwards, T., McBride, B.C. New method for the isolation and identification of methanogenic bacteria. Appl Microbiol., 1975; 29, 540-45.

12. Garcia, J.L., Patel, B.K.C., Ollivier, B. Taxonomic, phylogenetic and ecological diversity of methanogenic archaea. Anaerobe.,2000; 6: 205-26.

13. Hungate, R.E. The anerobic mesophilic cellulolytic bacteria. Bacteriol Rev., 1950; 14: 1-49. 
14. Hungate, R.E. A roll-tube method for cultivation of strict anaerobes. Methods Microbiol., 1969; 3B: 117-32.

15. Hungate, R.E., Smith, W., Clarke, R.T.J. Suitability of butyl rubber stoppers for closing anaerobic roll culture tubes. J Bacteriol., 1966; 91: 909.

16. Issazadeh, K., Nejati, P., Zare, F., Laczai, O. Diversity of methanogenic bacteria in ecological niches. Ann Biol Res., 2013; 4:36-42.

17. Jajesniak, P., Omar Ali, H.E.M., Wong, T.S. Carbon Dioxide Capture and Utilization using Biological Systems: Opportunities and Challenges. J Bioprocess Biotech., 2014; 4: 155.

18. Joulian, C., Ollivier, B., Patel, B.K.C., Roger, P.A. Phenotypic and phylogenetic characterization of dominant culturable methanogens isolated from rice field soils. FEMS Microbiol Ecol., 1998; 25: 135-45.

19. Kataoka, N., Tokiwa, Y., Takeda, K. Improved technique for identification and enumeration of methanogenic bacterial colonies of roll tubes by epifluorescence microscopy. Appl Environ Microbiol., 1991; 57:3671-73.

20. Leadbetter, J.R., Breznak, J.A. Physiological ecology of Methanobrevibactercuticularis sp. nov. and Methanobrevibactercurvatus sp. nov., isolated from the hindgut of the termite Reticulotermes flaviceps. Appl Environ Microbiol., 1996; 62: 3621-31.

21. McBride, B.C., Wolfe, R.S. A new coenzyme of methyl transfer, coenzyme M. Biochemistry., 1971; 10: 231724.

22. Miller, T.L., Wolin, M.J. A serum bottle modification of the Hungate technique for cultivating obligate anaerobes. Appl Microbiol., 1974; 27: 985-87.

23. Mink, R.W., Dugan, P.R. Tentative identification of methanogenic bacteria by fluorescence microscopy. Appl Environ Microbiol., 1977; 33: 713-17.

24. Mishra, V.P. Production of combustible gas and manure from bullock dung and other orgqanic materials. Ph.D thesis. IARI, New Delhi, 1954.

25. Ranade, D.R., Gadre, R.V. Principles of anaerobic techniques. In: Microbial Aspects of Anaerobic Digestion: Laboratory Manual, Pune: Maharashtra Association for the Cultivation of Science, Research Institute, Pune, India, 1988.

26. Riahi, K., Rubin, E.S., Schrattenholzer, L. (2004) Prospects for carbon capture and sequestration technologies assuming their technological learning. In: Gale, J and Y. Kaya (eds) Greenhouse Gas Control Technologies: Proceedings of the Sixth International Conference on Greenhouse Gas Control Technologies, Kyoto, Japan, Elsevier Science, Oxford, UK, 2004; pp 1095-1100.

27. Rittmann, S., Seifert, A., Herwig, C. Essential prerequisites for successful bioprocess development of biological $\mathrm{CH}_{4}$ production from $\mathrm{CO}_{2}$ and $\mathrm{H}_{2}$. Crit Rev Biotec., 2013; 35: 141-51.

28. Singh, S,L., Mazumder, P.B. Differential Approaches for Studying Methanogens: Methods, Analysis and Prospects. Assam Univ J Sci Technol., 2010; 6: 123-28.

29. Sowers, K.R. Methanogenic Archaea: an overview. In: Archaea: a Laboratory Manual: Methanogens, Sowers K R \& Schreier H J. (eds) Cold Spring Harbor, NY: Cold Spring Harbor Laboratory, 1995; pp 3-13.

30. Sowers, K.R., Schreier, H.J. In Archaea: a Laboratory Manual: Methanogens, Media for methanogens, Sowers, K.R., Schreier, H J. (eds) Cold Spring Harbor, NY: Cold Spring Harbor Laboratory; 1995; pp 459-89.

31. Styring, P., Armstrong, K. Catalytic carbon dioxide conversions to value- added chemicals. Chim Oggi., 2011; 29: 34-7.

32. Todar, K. Todar's online textbook of bacteriology. Madison, WI, Kenneth Todar, 2009.

33. Whitman, W., Bowen, T., Boone, D.R. The methanogenic bacteria. In: Dworkin, M., Falkow, S., Rosenberg, E., Schleifer, K.H., Stackerbrandt, E (eds) The prokaryotes. Springer-Verlag, New York, 2006; pp165-207.

34. Wolfe, R.S. Techniques for cultivating methanogens. Methods Enzymol., 2011; 494: 1-22. 